\title{
Dyspraxic Gait due to Right Posterior Cerebral Artery Stroke
}

Sir,

A 69-year-old male presented with confusion and visual disturbance, which had abruptly started $4 \mathrm{~h}$ before admission. At admission to the emergency department, he was cooperated, but orientation to place and timing was impaired. Left partial homonymous hemianopsia was detected. Motor and sensorial system examinations were in normal ranges. Cranial computed tomography showed hypodense area in the right posterior cerebral artery (PCA) territory [Figure 1]. Antiplatelet and anticoagulant therapies were initiated. Further investigations for the determination of stroke etiology including brain/neck tomography angiography, echocardiography, and electrocardiography were in normal ranges. However, $24 \mathrm{~h}$ Holter monitoring revealed paroxysmal atrial fibrillation which led to the initiation of warfarin. On the other hand, the patient's consciousness gradually improved in the following course, and on the $5^{\text {th }}$ day of stroke, he was appropriately cooperated and orientated. On neurological examination 2 weeks later, homonymous hemianopsia was not detected. Repeated motor and sensorial examinations including light touch sensation, proprioceptive, and temperature sensations were in normal ranges. Extrapyramidal signs including rigidity, bradykinesia, tremor, and bradymimia were also evaluated to be negative. However, broad-based gait which was compatible with apraxic gait was apparent [Video 1]. After warfarin dosage adjustments, he was referred to physical medicine and rehabilitation.

Gait disorders are extremely common manifestations in most of the neurological disorders. Among these, higher level gait disorders can be the most common, but, in contrary, the least recognized subtype of gait disorders. ${ }^{[1]}$ Higher level gait disorders can be described as gait abnormalities which cannot be explained by demonstrable deficit in pyramidal, extrapyramidal, sensory, or cerebellar systems. ${ }^{[2]}$ Vascular disease is a common cause of this kind of gait abnormalities which may be more specifically defined as "vascular gait dyspraxia." [1] In our patient, soon after the stroke, broad-based gait was determined. However, extrapyramidal examinations were in normal ranges, ruling out vascular parkinsonism. Hence, I prefer to define this patient as "vascular gait dyspraxia" due to right PCA stroke. The effected regions were right lateral thalamus and occipitotemporal lobes. Considering the clear temporal relation with stroke and gait dyspraxia, which is an extremely rare illustration, this report may contribute substantial insights regarding the physiology of gait control.

Remarkably, the role of thalamus in locomotion has been focused on in recent studies. ${ }^{[3,4]}$ Based on the considerable function of thalamus in some, specific cognitive processes, it has been hypothesized to play a more prominent role in locomotion than the other basal ganglia structures. ${ }^{[3]}$ Specifically, a lateral nuclear group of the thalamus (corresponding to the lesion site in our patient) is known to have connections with cortical regions including parietal, occipital, and temporal cortex which constitute association cortex and its role in processing and relaying sensory information to the cortex has been particularly emphasized. ${ }^{[5]}$ On the other hand, gait disturbances and some specific forms of locomotor disturbances such as "freezing of gait" are strongly 


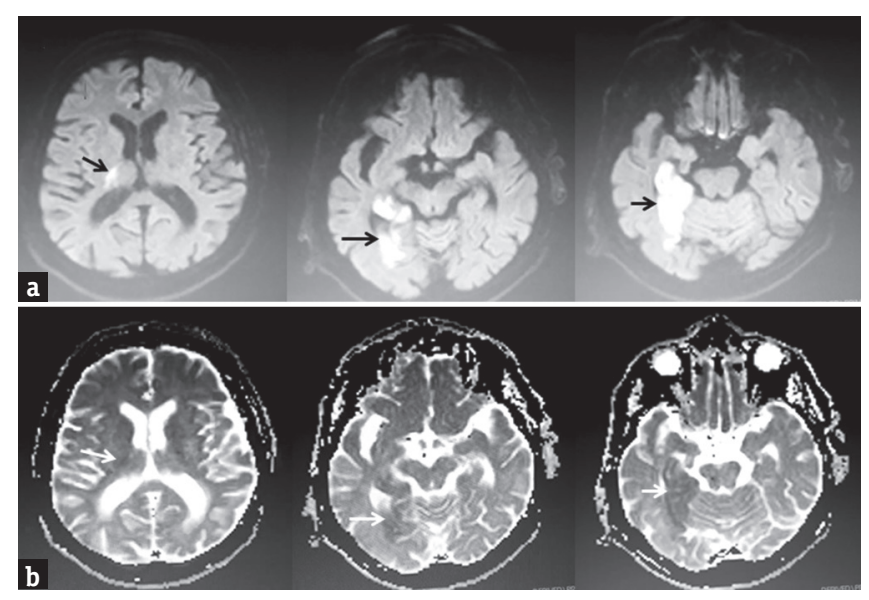

Figure 1: ( $\mathrm{a}$ and $\mathrm{b}$ ) Cranial magnetic resonance imaging showing high signal in the diffusion-weighted imaging sequences and low signal in $\mathrm{ADC}$ sequences in the diffusion restricted regions involving the lateral part of thalamus and occipitotemporal lobes (arrows). Of note, the regions corresponding to ventral posterolateral, ventral posteromedial, and centromedian nuclei of thalamus seem to be spared from ischemic injury

linked with perceptual impairments related to visuomotor integration of one's body within the environment which is a higher cortical function pertaining to association cortex. ${ }^{[6]}$ Combining these knowledges, I hypothesize that the gait apraxia, in this case, might be related to disruption of visuospatial perception developing due to thalamic stroke.

On another aspect, in our patient, ischemic lesion site also involved the region at the junction of temporal, occipital, and parietal lobes which is acknowledged as posterior association cortex. This might also have contributed to this clinical output. An important point may be that the clinical presentation of this ischemic stroke, which was lateralized to the right hemisphere, was in the form of broad-based gait and not any lateralized neurological deficit. In my opinion, this rather supports the view of a disturbance of higher cortical functions such as visuospatial functions, in which' impairment has been accused to be responsible from most forms of gait apraxia including freezing of gait. ${ }^{[7]}$

However, PCA stroke classically presents with acute vision loss, confusion, lateralized paresthesia, limb weakness, memory, and language disturbances. However, why was it in the form of broad-based gait in our patient, which is extremely rare, may be a crucial point of discussion. An explanation may be that preserving of sensorial, motor functions and consciousness state in our patient due to sparing of some specific thalamic nuclei such as ventral posterolateral, ventral posteromedial, and centromedian nuclei might have an influence in this clinical picture. I also think that gait dyspraxia might be an underestimated as well as underdiagnosed condition, as it constitutes only a subtle complaint for the patient and usually more devastating (hence remarkable) symptoms (such as paresthesia, paralysis, apathy, and aphasia) accompany to the clinic. Of note, the patient and his relatives had not stated this complaint spontaneously. However, when it was particularly questioned, they clearly stated the newly onset abnormal gait pattern according to premorbid state.

In conclusion, herein, I present a remarkable patient manifesting with broad-based gait due to right PCA stroke. The presentation of this case might give substantial insights regarding the pathophysiology of gait dyspraxia. Future reports of large case series are warranted to clarify these arguments. Focusing walking patterns of stroke patients without devastating and lateralized neurological deficits might give substantial perspectives from this aspect.

\section{Declaration of patient consent}

The authors certify that they have obtained all appropriate patient consent forms. In the form the patient(s) has/have given his/her/their consent for his/ her/their images and other clinical information to be reported in the journal. The patients understand that their names and initials will not be published and due efforts will be made to conceal their identity, but anonymity cannot be guaranteed.

\section{Financial support and sponsorship}

Nil.

\section{Conflicts of interest}

There are no conflicts of interest.

\section{Halil Onder}

Department of Neurology, Yozgat City Hospital, Yozgat, Turkey

Address for correspondence: Dr. Halil Onder, Department of Neurology, Yozgat State Hospital, Yozgat, Turkey. E-mail: halilnder@yahoo.com

\section{REFERENCES}

1. Briggs R, O’Neill D. Vascular gait dyspraxia. Clin Med (Lond) 2014;14:200-2.

2. Liston R, Mickelborough J, Bene J, Tallis R. A new classification of higher level gait disorders in patients with cerebral multi-infarct states. Age Ageing 2003;32:252-8.

3. Motl RW, Zivadinov R, Bergsland N, Benedict RH. Thalamus volume and ambulation in multiple sclerosis: A cross-sectional study. Neurodegener Dis Manag 2016;6:23-9.

4. Dumurgier J, Crivello F, Mazoyer B, Ahmed I, Tavernier B, Grabli D, et al. MRI atrophy of the caudate nucleus and slower walking speed in the elderly. Neuroimage 2012;60:871-8.

5. Tennant KA, Taylor SL, White ER, Brown CE. Optogenetic rewiring of thalamocortical circuits to restore function in the stroke injured brain. Nat Commun 2017;8:15879. 
6. Almeida QJ, Lebold CA. Freezing of gait in Parkinson's disease: A perceptual cause for a motor impairment? J Neurol Neurosurg Psychiatry 2010;81:513-8.

7. Nantel J, McDonald JC, Tan S, Bronte-Stewart H. Deficits in visuospatial processing contribute to quantitative measures of freezing of gait in Parkinson's disease. Neuroscience 2012;221:151-6.

This is an open access article distributed under the terms of the Creative Commons Attribution-NonCommercial-ShareAlike 3.0 License, which allows others to remix, tweak, and build upon the work non-commercially, as long as the author is credited and the new creations are licensed under the identical terms.
Video available on: www.ruralneuropractice.com

Access this article online

Quick Response Code:

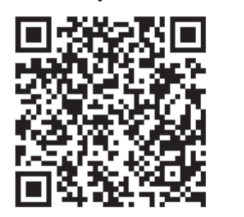

Website:

www.ruralneuropractice.com

DOI:

10.4103/jnrp.jnrp_314_17

How to cite this article: Onder $\mathrm{H}$. Dyspraxic gait due to right posterior cerebral artery stroke. J Neurosci Rural Pract 2018;9:162-4.

(c) 2018 Journal of Neurosciences in Rural Practice | Published by Wolters Kluwer - Medknow 